\title{
EFEITO DA APLICAÇÃO FOLIAR DE ÁCIDOS GRAXOS NA “VIA DAS LIPOXIGENASES” DE PLANTAS DE SOJA
}

\author{
Rosa Bárbara Batista, Maria Goreti de Almeida Oliveira*, Christiano Vieira Pires, Anna Cristina Lanna, Maria Regina Araújo \\ Gomes, Inês Chamel José, Newton Deniz Piovesan, Sebastião Tavares de Rezende e Maurilio Alves Moreira \\ Departamento de Bioquímica e Biologia Molecular, Universidade Federal de Viçosa, 36571-000 Viçosa - MG
}

Recebido em 2/7/01; aceito em 21/1/02

\begin{abstract}
EFFECT OF THE APLICATION OF FATTY ACIDS ON "LIPOXYGENASE PATHWAY" FROM SOYBEAN LEAVES. The involvement of lipoxygenase isozymes in several physiological processes of plants has been described but their role is not well understood and more biochemical studies are needed to elucidate the role of the "Lipoxygenase Pathway" in plant physiology. Thus, the biochemical and kinetic characterization of a lipoxygenases "pool" from soybean leaves was carried out. Two genotypes were used: IAC-100 (a normal variety having lipoxygenases in the seeds) and IAC-100 TN (genetically modified genotype, which is devoid of lipoxygenases in the seeds). The plants were submitted to the application of fatty acids (lipoxygenase substrates) on leaves. The results of the biochemical and kinetic studies of lipoxygenase isozymes from leaves of the two genotypes analysed showed that genetic removal of lipoxygenase from seeds did not affect the response of the plant to the treatment, since both genotypes showed similar results.
\end{abstract}

Keywords: lipoxygenase; fatty acids; soybean.

\section{INTRODUÇÃO}

Lipoxigenases (linoleato: oxigênio oxidorredutase, EC 1.13.11.12), pertencentes à classe das oxirredutases, são dioxigenases que catalisam a adição molecular de oxigênio às moléculas de ácidos graxos poliinsaturados, possuindo isomerismo geométrico, no sistema cis,cis-1,4-pentadieno ${ }^{1}$.

As lipoxigenases do sistema animal utilizam preferencialmente o ácido araquidônico como substrato e estão envolvidas na formação de vários componentes regulatórios, como leucotrienos e lipoxinas ${ }^{2}$. Assim, as lipoxigenases do sistema animal desempenham funções na inflamação, imunidade, hipersensibilidade e nas reações de defesa do hospedeiro.

No sistema vegetal, as lipoxigenases ocorrem em várias partes da planta, desempenhando funções em processos tais como: crescimento e desenvolvimento ${ }^{1}$, senescência ${ }^{3}$, reserva vegetativa ${ }^{4}$, germinação de sementes ${ }^{5}$, resposta a ferimento ${ }^{6}$ e resistência a insetos e patógenos ${ }^{7}$.

Os principais substratos de lipoxigenases, em plantas superiores, são os ácidos linoléico e linolênico ${ }^{8}$. $\mathrm{O}$ ácido linolênico é o mais abundante ácido graxo na maioria dos tecidos de plantas, compreendendo mais que $80 \%$ do grupo acil dos lipídios de membrana dos cloroplastos. $\mathrm{O}$ ácido linoléico se encontra em maior concentração nas sementes e embriões ${ }^{9}$ e, em plantas, pode ser convertido em ácido linolênico pela ação de uma dessaturase ${ }^{10}$.

A "Via das Lipoxigenases" em plantas está envolvida na síntese de moléculas regulatórias ${ }^{10}$. Os hidroperóxidos formados pela ação das lipoxigenases são moléculas reativas, e podem ser mobilizadas, em plantas superiores, por meio de um complexo mecanismo que envolve a hidroperóxido ciclase e a hidroperóxido liase.

A hidroperóxido liase produz compostos carbonílicos de seis carbonos como o trans-2-hexenal, o qual é um componente característico do sabor e odor de frutos e folhas verdes. Produz também

\footnotetext{
*e-mail: malmeida@mail.ufv.br
}

compostos de 12 carbonos como a traumatina, conhecida como hormônio do ferimento, e pode estar envolvida no processo de sinalização e divisão celular em resposta a ferimento ${ }^{11}$.

A hidroperóxido ciclase produz o ácido 12-oxo-fitodienóico que, após uma redução e três ß-oxidações, dá origem ao ácido jasmônico, o qual é um poderoso indutor da síntese de inibidores de proteases quando plantas são injuriadas ${ }^{12}$, além de ser indutor da expressão gênica de lipoxigenases em folhas primárias, hipocótilos e cotilédones ${ }^{13}$.

A função de lipoxigenases de plantas, sob o ponto de vista da relação estrutura/função, ainda não está bem clara ${ }^{14}$. Assim, torna-se cada vez mais importante estudos bioquímicos visando elucidar a participação da "Via das Lipoxigenases" na fisiologia da planta, em especial no mecanismo de defesa da soja a insetos e patógenos.

O objetivo deste trabalho foi avaliar a capacidade da planta em responder à aplicação de ácidos graxos, substratos de lipoxigenases, por meio da "Via das Lipoxigenases" sendo utilizadas duas isolinhas de soja: uma variedade normal, IAC-100, contendo as três isoenzimas lipoxigenases na semente, e o genótipo IAC-100 TN, modificado geneticamente, apresentando ausência completa das três isoenzimas lipoxigenases nas sementes.

\section{PARTE EXPERIMENTAL}

\section{Material genético}

Foram utilizadas plantas de soja (Glycine max (L.) Merrill) da variedade IAC-100 e do genótipo com ausência de lipoxigenases nas sementes (IAC-100 TN). O genótipo IAC-100 TN, desenvolvido pelo Programa de Melhoramento da Qualidade da Soja do BIOAGRO/ UFV, é uma linhagem avançada obtida a partir da variedade IAC 100 que se encontra no sexto ciclo de retrocruzamentos, terceira geração de autofecundação. A alta similaridade genética entre IAC 100 e IAC - 100 TN foi confirmada por meio de análise de DNA, utilizando-se marcadores moleculares do tipo RAPD "Random Amplified Polymorphic DNA", e também por meio de característi- 
cas fenotípicas. As plantas foram cultivadas em vasos com capacidade para 3,0 Kg de solo, em condições de casa de vegetação.

\section{Aplicação de ácidos graxos}

As plantas de soja no estádio V2 de desenvolvimento (primeira folha trifoliolar completamente expandida), tiveram este trifolíolo isolado e pulverizado em dias alternados, com soluções a $10 \mathrm{mM}$ de ácidos graxos (araquidônico, linoléico e linolênico) contendo Triton X$1000,01 \%(\mathrm{v} / \mathrm{v})^{10}$ até atingirem o estádio V3 de desenvolvimento (segunda folha trifoliolar completamente expandida). Plantas controle receberam aplicação da solução aquosa de Triton X-100 0,01\% (v/v).

Foram utilizadas, como fonte de enzima, a primeira e a segunda folhas trifoliolares de plantas de soja no estádio V3 de desenvolvimento ${ }^{15}$. Os três folíolos da primeira e da segunda folhas trifoliolares foram coletadas 0,24 e $48 \mathrm{~h}$ após a última aplicação das soluções dos ácidos graxos, congeladas em nitrogênio líquido e armazenadas a $-80{ }^{\circ} \mathrm{C}$. O preparo do extrato bruto foi realizado a $4{ }^{\circ} \mathrm{C}$, de acordo com o método descrito por Ohta et al. ${ }^{16}$.

\section{Determinação da atividade de lipoxigenases}

A atividade de lipoxigenase sobre o ácido linoléico foi determinada segundo o método descrito por Axelrod et al.$^{17}$. O método baseia-se no aumento da absorvância a $234 \mathrm{~nm}$, resultante da formação de um sistema de duplas ligações conjugadas no hidroperóxido formado.

\section{Determinação da atividade de lipoxigenase em vários valores de $\mathbf{p H}$}

Os seguintes sistemas-tampão foram usados: ácido cítrico/fosfato dissódico (2,0-2,5); ácido cítrico/citrato de sódio (3,0-3,5); ácido acético/acetato de sódio (4,0-4,5); ácido cítrico/citrato de sódio (5,05,5); monofosfato/fosfato dissódico $(6,0-7,0)$; Tris- $\mathrm{HCl}(7,5-8,5)$ e ácido bórico/borato de sódio $(9,0-10,0)$, na concentração de $50 \mathrm{mM}$. A absorvância da mistura de reação a $234 \mathrm{~nm}$ foi determinada de 30 em $30 \mathrm{seg}$ por um período de $2,5 \mathrm{~min}$, a $25^{\circ} \mathrm{C}$.

\section{Determinação da atividade de lipoxigenases em vários valores de temperatura}

Foi determinada a taxa de oxidação do ácido linoléico pelas lipoxigenases a $20,25,30,35,40,45$ e $50{ }^{\circ} \mathrm{C}$. Utilizou-se banhomaria bem como espectrofotômetro com temperatura controlada.

\section{Determinação da concentração de proteínas}

As determinações das concentrações de proteínas foram feitas pelo método do ácido bicinconínico ${ }^{18}$. Este método utiliza a albumina sérica bovina como padrão e o "kit" SIGMA como reagente de trabalho, que constituiu de uma solução de ácido bicinconínico e uma solução de sulfato de cobre (II) - pentaidratado $4 \%$ (p/v). O aumento da absorvância foi determinado a $562 \mathrm{~nm}$.

\section{Determinação de inibidores de proteases}

A determinação de inibidores de proteases nos extratos foliares foi realizada baseada na inibição da atividade da tripsina utilizandose $\left(\mathrm{N} \alpha\right.$-Benzoil- ${ }_{\mathrm{DL}}$-Arginina p-Nitroanilida) ${ }_{\mathrm{D}, \mathrm{L}}{ }^{-}$BApNA como substrato. Os resultados obtidos foram convertidos em miligrama de tripsina inibida por grama de proteína, de acordo com o método descrito por Kakade et al. ${ }^{19}$.

\section{Determinação dos níveis de hexanal e aldeídos totais}

A determinação de hexanal foi realizada por cromatografia gasosa, pelo método do "head-space", segundo Utumi et al. ${ }^{20}$. Utilizou-se coluna carbowax $(2500 \mathrm{~cm}$ x $0,53 \mathrm{~mm})$, e o gás de arraste foi o nitrogênio, com fluxo de $5,7 \mathrm{~mL} / \mathrm{min}$. A identificação de hexanal foi feita por injeção prévia do composto-padrão, e os resultados foram expressos em área do pico, em milivolts.

Nas determinações de aldeídos foi utilizado o método colorimétrico desenvolvido por Santos et al. . $^{21}$, utilizando-se 3-metil2-benzotiazolinona hidrazona (MBTH) como reagente de cor. As leituras da absorvância foram realizadas a $635 \mathrm{~nm}$, sendo os resultados expressos como a diferença da absorvância observada ao final da reação e na reação controle.

\section{RESULTADOS E DISCUSSÃO}

\section{Efeito do pH sobre a atividade de lipoxigenases}

Com o objetivo de caracterizar o pH ótimo de atuação de lipoxigenases foliares de plantas de soja submetidas à aplicação de substratos exógenos, realizou-se as análises de efeito de $\mathrm{pH}$ sobre a atividade enzimática. A Figura 1 apresenta os perfis das curvas de $\mathrm{pH}$ versus atividade específica de lipoxigenases. Os perfis para os ácidos araquidônico $\left(\mathrm{C}_{20: 4}\right)$, e linoléico $\left(\mathrm{C}_{18: 2}\right)$, em todos os tempos analisados, e para o ácido linolênico $\left(\mathrm{C}_{18: 3}\right)$ nos tempos 0 e 24 h após aplicação, apresentaram-se semelhantes.

Pode-se observar dois picos mais acentuados de atividade específica de lipoxigenases a $\mathrm{pH}$ 4,5 e 6,0, nos tratamentos e em seus respectivos controles, tanto para a resposta local quanto para a resposta sistêmica. Em pH 4,5 o valor de atividade específica foi semelhante para os dois genótipos analisados, resposta local e sistêmica, entretanto, em pH 6,0 o valor de atividade específica foi maior na resposta local do que na resposta sistêmica. Observa-se ainda, que as plantas tratadas com os substratos de lipoxigenases apresentaram valores de atividade específica maiores do que os respectivos controles. Esses resultados sugerem que, com a adição de substrato exógeno possivelmente tenha ocorrido aumento na atividade enzimática.

Tanto na resposta local quanto na resposta sistêmica, a atividade específica em pH 6,0 apresentou-se maior do que a atividade específica em $\mathrm{pH} 4,5$, sugerindo que o "pool" de lipoxigenases contém mais de uma forma das isoenzimas.

Os valores de $\mathrm{pH}$ ótimo para a formação de hidroperóxidos do ácido linoléico catalisada pelas lipoxigenases de folhas de soja da variedade IAC-100 e do genótipo IAC-100 TN, submetidas à aplicação de ácidos graxos nas folhas, estão dentro da faixa de pH ótimo verificada para lipoxigenases de outras plantas, encontrada por vários autores em outros estudos: lipoxigenases de tubérculos de batata,

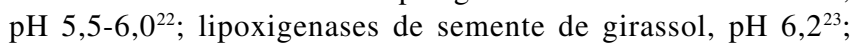
lipoxigenases de folhas de tomate inoculadas com Pseudomonas, $\mathrm{pH}$ 6,4-7,2 $2^{24}$; lipoxigenases de pepino, $\mathrm{pH} 5,0^{25}$; lipoxigenases de pimentão, $\mathrm{pH} 6,5^{26}$; lipoxigenases de semente de ervilha, $\mathrm{pH} 6,8^{27} \mathrm{e}$ lipoxigenases de folhas de soja do genótipo IAC-100 e IAC-100 TN, no estádio V3 de desenvolvimento, submetidas a ferimento mecânico, $\mathrm{pH} 6,0^{6}$.

\section{Efeito da temperatura sobre a atividade de lipoxigenases}

Para determinar o valor da temperatura ótima de atividade de lipoxigenases foliares de plantas de soja submetidas à aplicação de ácidos graxos foi realizada uma análise de atividade, a vários valores de temperatura. A Figura 2 apresenta os perfis das curvas de temperatura versus atividade específica de lipoxigenases. Os perfis para os 


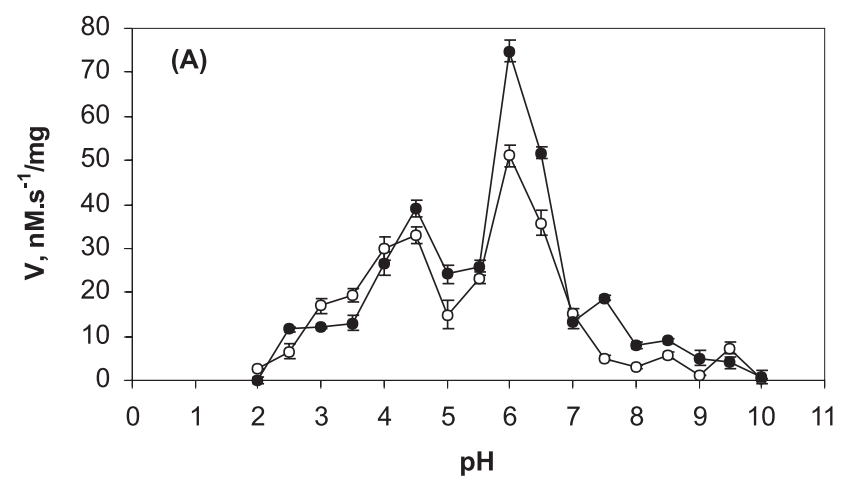

- $\_$resposta local (folíolos da primeira folha trifoliolar) de plantas controle

$\multimap$ resposta local (folíolos da primeira folha trifoliolar) de plantas tratadas

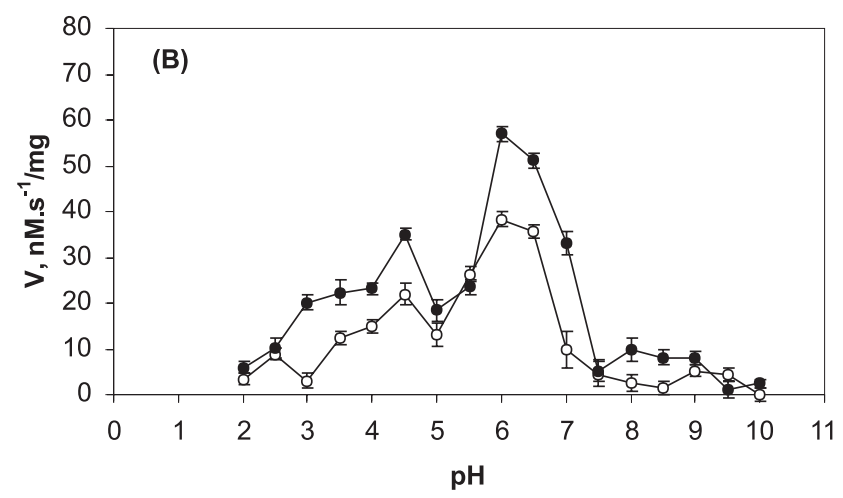

-

$\rightarrow$ resposta sistêmica (folíolos da segunda folha trifoliolar) de plantas tratadas

Figura 1. Atividade específica de lipoxigenases de folhas de soja em vários valores de $\mathrm{pH}$. Primeira e segunda folhas trifoliolares de plantas da variedade IAC-100 no estádio V3 de desenvolvimento, coletadas 48 h após a última aplicação de solução $10 \mathrm{mM}$ de ácido linolênico $\left(C_{18: 3}\right)$ em Triton $X-1000,01 \%(v / v)$, e seus respectivos controles [aplicação de solução aquosa de Triton $X-1000,01 \%(v / v)]$. Valores são a média de três repetições \pm desvio padrão.

Condições experimentais: $1000 \mu \mathrm{L}$ de tampão fosfato $50 \mathrm{mM}, 25^{\circ} \mathrm{C} ; 4 \mu \mathrm{L}$ de linoleato de sódio $10 \mathrm{mM} ; 1 \mu \mathrm{L}$ de extrato bruto foliar.

Quantidade de proteína no ensaio: Em (A): 0,10 mg (controle) e 0,70 mg (tratamento). Em (B): e 0,10 mg (controle) e 0,50 mg (tratamento).

ácidos araquidônico $\left(\mathrm{C}_{20: 4}\right)$, e linoléico $\left(\mathrm{C}_{18: 2}\right)$, em todos os tempos analisados, e para o ácido linolênico $\left(\mathrm{C}_{18: 3}\right)$ nos tempos 0 e $24 \mathrm{~h}$ após aplicação, apresentaram-se semelhantes.

$\mathrm{O}$ valor mais acentuado de atividade específica foi a $25^{\circ} \mathrm{C}$, para ambos os genótipos e seus respectivos controles. O pico a $25^{\circ} \mathrm{C}$ foi o maior, porém não foi o único observado, mostrando novamente a presença de mais de uma forma de isoenzimas lipoxigenases. Verificou-se novamente, que a atividade específica foi maior nas plantas submetidas à aplicação foliar de ácidos graxos do que nos respectivos controles, sugerindo uma resposta das plantas de soja ao tratamento através do aumento da atividade de lipoxigenases, como verificado nas análises de efeito do $\mathrm{pH}$.

Esses resultados estão de acordo com os citados na literatura, visto que outros autores obtiveram valor de temperatura ótima de $25{ }^{\circ} \mathrm{C}$ para lipoxigenases foliares de soja: Lanna et al. ${ }^{28}$ trabalhando com plantas dos genótipos IAC-100, UFV-TN e Cristalina, no está-

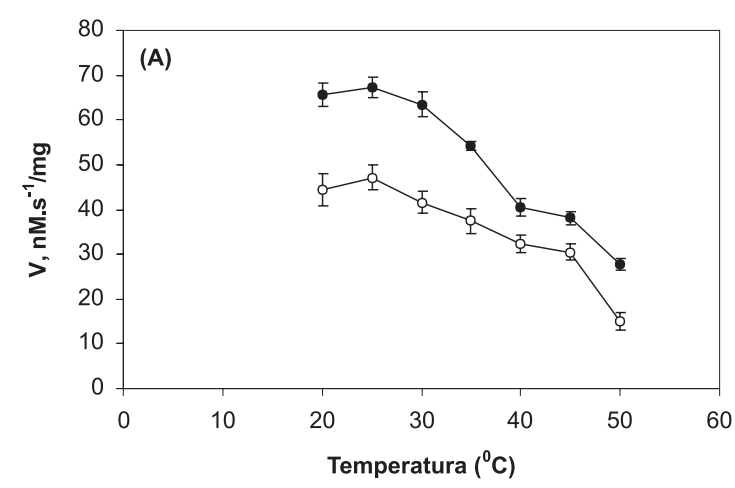

$\multimap$ resposta local (primeira folha trifoliolar) de plantas controle
$\rightarrow$ resposta local (primeira folha trifoliolar) de plantas tratadas

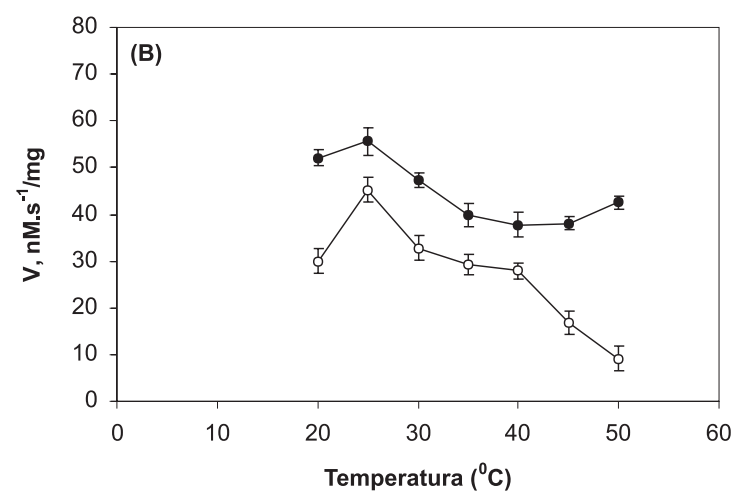

-o- resposta sistêmica (segunda folha trifoliolar) de plantas controle $\rightarrow$ resposta sistêmica (segunda folha trifoliolar) de plantas tratadas

Figura 2. Atividade específica de lipoxigenases de folhas de soja em vários valores de temperatura. Primeira e segunda folhas trifoliolares de plantas do genótipo IAC-100 TN no estádio V3 de desenvolvimento, coletadas $48 \mathrm{~h}$ após a última aplicação de solução $10 \mathrm{mM}$ de ácido linolênico $\left(C_{18: 3}\right) \mathrm{em}$ Triton X-100 0,01\% (v/v), e seus respectivos controles [aplicação de solução aquosa de Triton X-100 0,01\% (v/v)]. Valores são a média de três repetições \pm desvio padrão.

Condições experimentais: $1000 \mu \mathrm{L}$ de tampão fosfato $50 \mathrm{mM}, \mathrm{pH}$ 6,0; $4 \mu \mathrm{L}$ de linoleato de sódio $10 \mathrm{mM} ; 1 \mu \mathrm{L}$ de extrato bruto foliar.

Quantidade de proteína no ensaio: Em (A): 1,26 mg (controle) e 1,36 mg (tratamento). Em (B): e 0,82 mg (controle) e 1,78 $\mathrm{mg}$ (tratamento).

dio V4 de desenvolvimento; Vieira et al. ${ }^{6}$ analisando plantas da variedade IAC-100 e do genótipo IAC-100 TN, no estádio V3 de desenvolvimento, submetidas a ferimento mecânico.

\section{Atividade específica de lipoxigenases}

A determinação da atividade específica de lipoxigenases nos experimentos foi realizada a $\mathrm{pH}$ 6,0 e em tampão fosfato de sódio $50 \mathrm{mM}$ a $25^{\circ} \mathrm{C}$, pelo fato desses valores de $\mathrm{pH}$ e temperatura terem sido aqueles em que houve maiores picos de atividade. As Figuras 3 e 4 apresentam os valores de atividade específica de lipoxigenases, utilizando-se o ácido linoléico como substrato.

$\mathrm{Na}$ variedade IAC-100 (Figura 3) houve um ligeiro aumento de atividade específica de 0 a 24 h após os tratamentos, entretanto, no genótipo IAC-100 TN (Figura 4) houve aumento de atividade específica de 0 a $48 \mathrm{~h}$ após os tratamentos, mas os valores de atividade espe- 

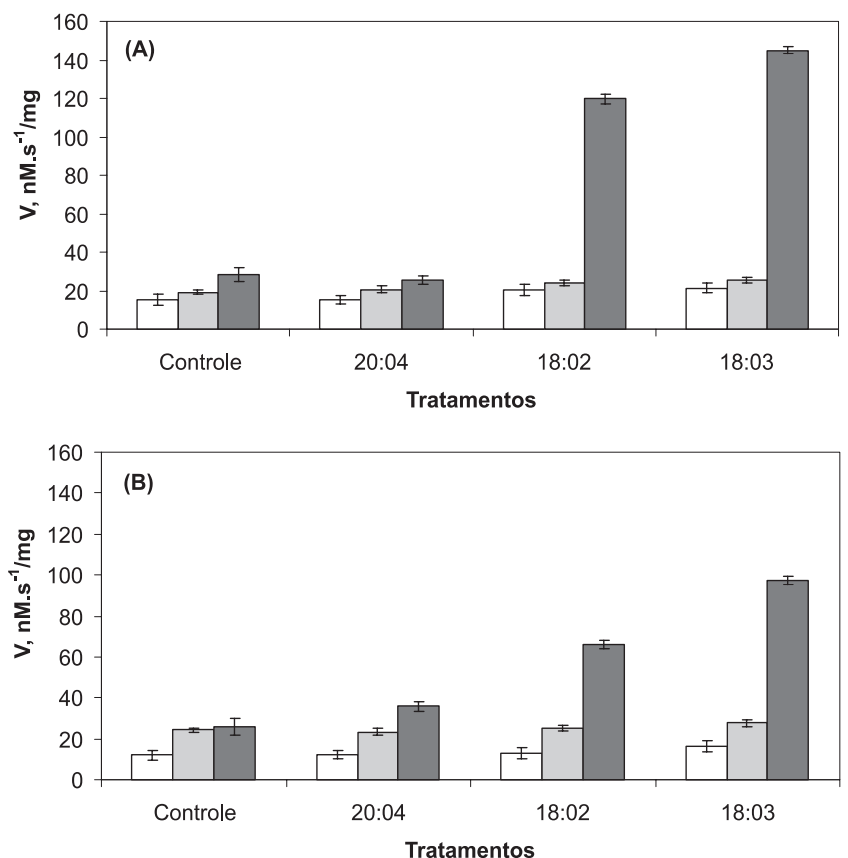

$\square$ atividade específica de plantas coletadas $0 \mathrm{~h}$ após a última aplicação de ácidos graxos $\square$ atividade específica de plantas coletadas $24 \mathrm{~h}$ após a última aplicação de ácidos graxos

$\square$ atividade específica de plantas coletadas $48 \mathrm{~h}$ após a última aplicação de ácidos graxos

Figura 3. Atividade especifica de lipoxigenases de folhas de soja, resposta local (primeira folha trifoliolar) (A) e resposta sistêmica (segunda folha trifoliolar) (B) de plantas de soja da variedade IAC-100 no estádio V3 de desenvolvimento, coletadas 0,24 e 48 h após a última aplicação de solução $10 \mathrm{mM}$ dos ácidos araquidônico $\left(C_{20: 4}\right)$, linoléico $\left(C_{18: 2}\right)$ e linolênico $\left(C_{18: 3}\right)$ e seus respectivos controles [aplicação de solução aquosa de Triton X-100 $0,01 \%(v / v)]$. Valores são a média de três repetições \pm desvio padrão. Condições experimentais: $1000 \mu \mathrm{L}$ de tampão fosfato $50 \mathrm{mM}, \mathrm{pH}$ 6,0, $25{ }^{\circ} \mathrm{C} ; 4 \mu \mathrm{L}$ de linoleato de sódio $10 \mathrm{mM} ; 1 \mu \mathrm{L}$ de extrato bruto foliar

cífica de plantas do genótipo IAC-100 TN foram maiores que os de plantas da variedade IAC-100. Esses resultados mostram que, embora exista diferença no "pool" de lipoxigenases entre as duas isolinhas, o comportamento cinético enzimático das mesmas é semelhante, evidenciando assim, que a remoção genética das isoenzimas lipoxigenases da semente não afetou a resposta das folhas ao tratamento.

Para ambos os genótipos, os resultados mostraram maiores valores de atividade específica no tempo de $48 \mathrm{~h}$ após tratamento com os ácidos linoléico (18:2) e linolênico (18:3), os quais são os principais substratos de lipoxigenases no sistema vegetal. Porém, o tratamento com o ácido linolênico (18:3) foi o que apresentou maiores valores de atividade específica nos dois genótipos, respostas local e sistêmica, nos tempos de 24 e $48 \mathrm{~h}$ após tratamento. Possivelmente isso se deve ao fato deste ácido ser mais abundante nas folhas do que o ácido linoléico, logo, pode estar sendo utilizado pela planta como substrato exógeno. Além disso, o ácido linoléico pode ser convertido pelas plantas, por meio de uma dessaturase, em ácido linolênico, o qual dá origem ao ácido jasmônico que, por sua vez, ativa lipoxigenases ${ }^{10}$.

Em ambos os genótipos, observou-se que os valores de atividade específica das plantas tratadas com o ácido araquidônico $\left(\mathrm{C}_{20: 4}\right)$ foram semelhantes aos de plantas-controle, observando-se também, o efeito do Triton X-100. Acredita-se que, com a adição de substrato exógeno, possivelmente tenha ocorrido aumento na atividade de lipoxigenases. Para que pudesse ocorrer a passagem de ácidos graxos pela membrana, o Triton X-100 foi adicionado ao solvente. O Triton X-100 é um detergente que, quando em contato com membranas, liga-se às regiões lipofílicas das proteínas da membrana por sua extre-
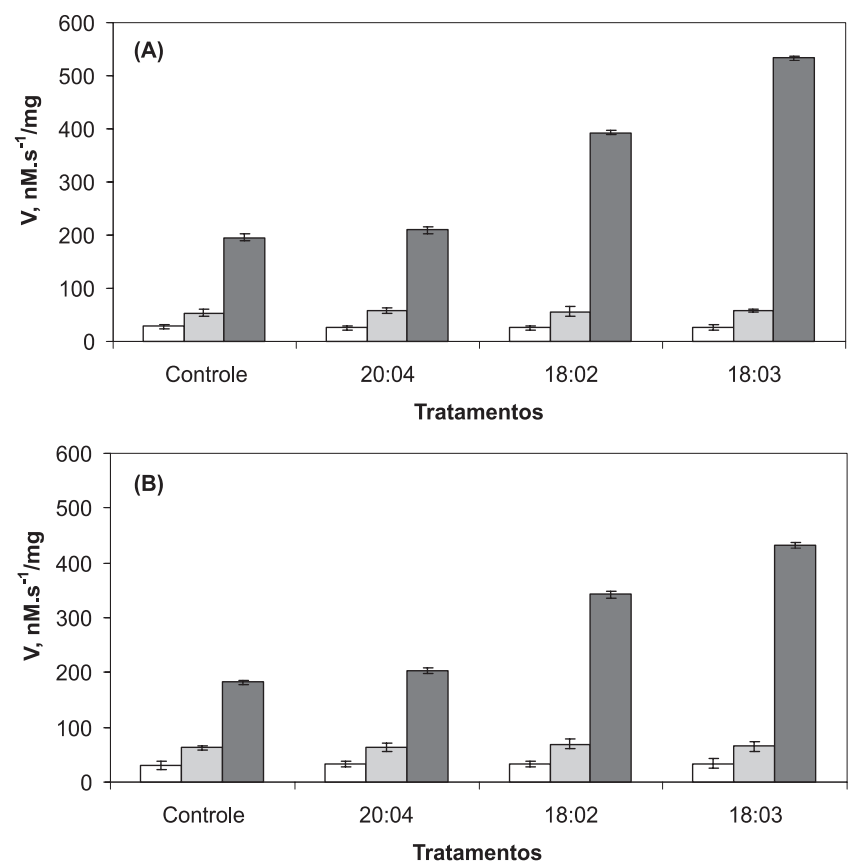

$\square$ atividade específica de plantas coletadas $0 \mathrm{~h}$ após a última aplicação de ácidos graxos $\square$ atividade específica de plantas coletadas $24 \mathrm{~h}$ após a última aplicação de ácidos graxos $\square$ atividade específica de plantas coletadas $48 \mathrm{~h}$ após a última aplicação de ácidos graxos

Figura 4. Atividade específica de lipoxigenases de folhas de soja, resposta local (primeira folha trifoliolar) (A) e resposta sistêmica (segunda folha trifoliolare) (B) de plantas de soja da variedade IAC-100 TN no estádio V3 de desenvolvimento, coletadas 0,24 e 48 h após a última aplicação de solução $10 \mathrm{mM}$ dos ácidos araquidônico $\left(C_{20: 4}\right)$, linoléico $\left(C_{18: 2}\right)$ e linolênico $\left(C_{18: 3}\right)$ e seus respectivos controles [aplicação de solução aquosa de Triton $X-1000,01 \%(v / v)]$. Valores são a média de três repetições \pm desvio padrão.

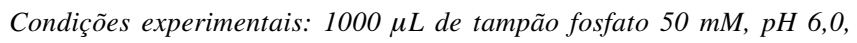
$25{ }^{\circ} \mathrm{C} ; 4 \mu \mathrm{L}$ de linoleato de sódio $10 \mathrm{mM} ; 1 \mu \mathrm{L}$ de extrato bruto foliar.

midade hidrofóbica, deslocando as moléculas lipídicas. Este deslocamento pode desestruturar a bicamada lipídica, tornando a membrana mais permeável e, dessa forma, aumentando o fluxo de moléculas. Como a outra extremidade da molécula do detergente é polar, essa ligação tende a solubilizar as proteínas da membrana como complexos de detergente-proteína. Assim, o aumento da atividade pode ter sido ocasionado pela utilização do substrato exógeno que aumentou a atividade enzimática devido ao aumento da concentração de substrato no meio, ou porque ocorreu aumento de síntese de lipoxigenases, ou até mesmo os dois casos.

\section{Inibidores de proteases}

Como a "Via das Lipoxigenases" pode produzir ácido jasmônico, e este ativa genes que codificam inibidores de protease $^{10}$, realizouse a determinação da inibição tríptica frente aos extratos foliares. Os resultados em miligrama de tripsina inibida por grama de proteína encontram-se apresentados nas Tabelas 1 e 2.

Foi observada inibição tríptica significativa 48 h após a última aplicação dos ácidos linoléico e linolênico, os quais são os principais substratos de lipoxigenases no sistema vegetal. Isto ocorreu tanto na resposta local quanto na sistêmica, nos dois genótipos analisados. Assim, houve resposta da planta aos tratamentos, por meio da produção de inibidores de serinoproteases, provavelmente pela ativação da "Via das Lipoxigenases". Estes resultados estão de acordo com os obtidos por Farmer e Ryan ${ }^{10}$ quando trabalharam com plantas de tomate submetidas à aplicação de vários ácidos graxos, incluindo os 
Tabela 1. Inibição de tripsina por inibidores de proteases presentes em extratos de folhas de soja, folíolos da primeira folha trifoliolar de plantas no estádio V3 de desenvolvimento. Variedade IAC-100 e genótipo IAC-100 TN coletados 0, 24 e 48 h após a última aplicação de solução $10 \mathrm{mM}$ dos ácidos araquidônico $\left(\mathrm{C}_{20: 4}\right)$, linoléico $\left(\mathrm{C}_{18: 2}\right)$ e linolênico $\left(\mathrm{C}_{18: 3}\right)$ e seus respectivos controles [aplicação de solução aquosa de Triton X-100 0,01\% (v/v)].

Condições experimentais: $500 \mu \mathrm{L}$ de tampão Tris- $\mathrm{HCl} 0,1 \mathrm{M}, \mathrm{pH} 8,2$ contendo $20 \mathrm{mM}$ de $\mathrm{CaCl}_{2} ; 100 \mu \mathrm{L}$ do extrato bruto foliar; $50 \mu \mathrm{L}$ de solução de tripsina $4,7 \times 10^{-5} \mathrm{M} ; 500 \mu \mathrm{L}$ de solução de D,L-BapNA $1,2 \mathrm{mM}$

\begin{tabular}{|c|c|c|c|c|c|c|c|c|}
\hline \multirow{4}{*}{$\begin{array}{l}\text { Tempo (Horas } \\
\text { após a última } \\
\text { aplicação das } \\
\text { soluçôes dos } \\
\text { ácidos graxos, } \\
\text { substratos de } \\
\text { lipoxigenases) }\end{array}$} & \multicolumn{8}{|c|}{ mg de tripsina inibida/grama de proteína } \\
\hline & \multicolumn{8}{|c|}{ Resposta local (folíolos da primeira folha trifoliolar) } \\
\hline & \multicolumn{4}{|c|}{ IAC-100 } & \multicolumn{4}{|c|}{ IAC-100 TN } \\
\hline & Controle & $\begin{array}{c}\text { Ácido } \\
\text { Araquidônico }\end{array}$ & $\begin{array}{c}\text { Ácido } \\
\text { Linoléico }\end{array}$ & $\begin{array}{c}\text { Ácido } \\
\text { Linolênico }\end{array}$ & Controle & $\begin{array}{c}\text { Ácido } \\
\text { Araquidônico }\end{array}$ & $\begin{array}{c}\text { Ácido } \\
\text { Linoléico }\end{array}$ & $\begin{array}{c}\text { Ácido } \\
\text { Linolênico }\end{array}$ \\
\hline 0 & $5,0454^{1} \mathbf{a g}$ & 5,6471 ag & $5,8240 \mathbf{a}$ & $7,4156 \underline{\mathbf{a}}$ & $6,7940 \mathbf{d g A}$ & $5,9580 \mathbf{d g A}$ & $10,0109 \underline{\mathbf{d}}$ & $11,4573 \underline{\mathbf{d} B}$ \\
\hline 24 & $9,0791 \mathbf{b}$ & $10,3312 \underline{\mathbf{b}}$ & $10,6479 \mathbf{b b}$ & $13,5785 \underline{\mathbf{b h}}$ & $7,3312 \mathbf{e A}$ & $5,7943 \mathbf{e} \underline{\mathbf{A}}$ & $14,2957 \underline{\mathbf{e}}$ & 12,7260 ehB \\
\hline 48 & $40,4472 \mathbf{c}$ & $38,6397 \mathbf{c}$ & $88,0148 \underline{\mathbf{c}}$ & $96,6473 \underline{\mathbf{c}}$ & $31,5719 \mathbf{f}$ & $30,8527 \overline{\mathbf{f}}$ & $114,4251 \underline{\mathbf{f}}$ & $114,7830 \underline{\mathbf{f}}$ \\
\hline
\end{tabular}

${ }^{1}$ Valores são a média das análises de três repetições. Nas colunas, as médias seguidas de uma mesma letra maiúscula (ou maiúscula grifada) não diferem entre si, a 5\% de probabilidade, pelo teste de Tukey. Nas linhas, as médias seguidas de uma mesma letra minúscula (ou minúscula grifada) não diferem entre si, a $5 \%$ de probabilidade, pelo teste de Tukey.

Tabela 2. Inibição de tripsina por inibidores de proteases presentes em extratos de folhas de soja, folíolos da segunda folha trifoliolar de plantas no estádio V3 de desenvolvimento. Variedade IAC-100 e genótipo IAC-100 TN coletados 0, 24 e 48 h após a última aplicação de solução $10 \mathrm{mM}$ dos ácidos araquidônico $\left(\mathrm{C}_{20: 4}\right)$, linoléico $\left(\mathrm{C}_{18: 2}\right)$ e linolênico $\left(\mathrm{C}_{18: 3}\right)$ e seus respectivos controles [aplicação de solução aquosa de Triton X-100 0,01\% (v/v)].

Condições experimentais: iguais às da Tabela 1

mg de tripsina inibida/grama de proteína

Tempo (Horas após a última aplicação das soluções dos ácidos graxos, substratos de lipoxigenases)

\begin{tabular}{|c|c|c|c|c|c|c|c|c|}
\hline 0 & $8,0010^{1} \mathbf{a A}$ & $8,1447 \mathbf{a} \underline{\mathbf{A}}$ & $9,9001 \underline{\mathbf{a}}$ & $9,9981 \underline{\mathbf{a}}$ & $5,1610 \underline{\mathbf{d}}$ & $6,6892 \mathbf{e}$ & 6,6415 eB & $5,8153 \underline{\text { de }}$ \\
\hline 24 & $8,8258 \mathbf{b A}$ & 9,8891 bbga & 10,9438 bh & 10,4437 bh & $6,9906 \underline{\mathbf{e}}$ & $9,6413 \mathbf{f g}$ & 9,7765 fhB & $10,2313 \mathbf{f h}$ \\
\hline 48 & $37,7502 \mathbf{c}$ & 39,4740 c & $93,8676 \underline{\mathbf{c i}}$ & $109,9402 \mathbf{d i}$ & $25,7076 \underline{\mathbf{f}}$ & $26,7567 \underline{\mathbf{f}}$ & 98,9635 gi & 103,0259 gi \\
\hline
\end{tabular}

Ver rodapé da Tabela 1

ácidos araquidônico, linoléico e linolênico. A maioria dos ácidos utilizados foram inativos na indução da síntese de inibidor I, exceto os ácidos linoléico e linolênico. Os resultados obtidos por Farmer e Ryan ${ }^{10}$ indicam que os compostos ativos na síntese de inibidores de proteases em folhas de tomate foram convertidos em ácido jasmônico nas plantas, atuando como ativadores dos genes de inibidores proteases.

A maior produção de inibidores de proteases observada ocorreu $48 \mathrm{~h}$ após tratamento com o ácido linolênico, tanto na resposta local quanto na sistêmica em ambos os genótipos. Esses resultados também estão de acordo com os obtidos por Farmer e Ryan ${ }^{10}$, que observaram que os níveis de inibidor I que acumularam em resposta ao ácido linolênico foram muito maiores que aqueles induzidos por ácido linoléico e até mesmo por ferimento.

Os resultados obtidos, associados aos resultados de atividade específica, indicam um possível mecanismo de defesa da planta de soja à aplicação de ácidos graxos envolvendo a "Via das Lipoxigenases", que parece ocorrer através do aumento da eficiência catalítica de lipoxigenases e em seguida, sob a ação da hidroperóxido ciclase, o hidroperóxido formado é convertido em ácido 12-oxo-fitodienóico que, posteriormente é transformado em ácido jasmônico. Este, por sua vez, poderia interagir com um receptor de membrana a fim de ativar a expressão de genes que codificam inibidores de proteases ${ }^{10}$.

\section{Níveis de hexanal e de aldeídos totais}

A "Via das Lipoxigenases" pode produzir, também, hexanal e outros aldeídos ${ }^{29-30}$. Assim, realizou-se a determinação de hexanal e de aldeídos totais, com o objetivo de verificar se a aplicação de ácidos graxos, substratos de lipoxigenases, nas plantas de soja iria produzir aumento nos níveis de aldeídos. Os níveis de hexanal estão representados nas Tabelas 3 e 4 e os níveis de aldeídos totais nas Tabelas 5 e 6.

Houve um ligeiro aumento nos níveis de hexanal dos tratamentos quando comparados aos respectivos controles, na resposta local, em ambos os genótipos (Tabela 3), mas o mesmo não foi observado na resposta sistêmica (Tabela 4). Tanto a variedade IAC-100 quanto o genótipo IAC-100 TN não apresentaram aumento significativo nos 
Tabela 3. Níveis de hexanal presentes em extratos de folhas de soja, folíolos da primeira folha trifoliolar de plantas no estádio V3 de desenvolvimento. Variedade IAC-100 e genótipo IAC-100 TN coletados 0, 24 e 48 h após a última aplicação de solução 10 mM dos ácidos araquidônico $\left(\mathrm{C}_{20: 4}\right)$, linoléico $\left(\mathrm{C}_{18: 2}\right)$ e linolênico $\left(\mathrm{C}_{18: 3}\right)$ e seus respectivos controles [aplicação de solução aquosa de Triton $\mathrm{X}-100$ 0,01\% (v/v)].

Condições experimentais: $50 \mathrm{mg}$ de folhas liofilizadas e moídas; $1000 \mu \mathrm{L}$ de tampão fosfato $0,5 \mathrm{M}, \mathrm{pH} 7,0,40{ }^{\circ} \mathrm{C} / 20 \mathrm{~min}$; temperatura inicial da coluna: $45^{\circ} \mathrm{C}$; temperatura do injetor: $200{ }^{\circ} \mathrm{C}$; temperatura do detector: $250{ }^{\circ} \mathrm{C}$; coluna CARBOWAX $(2500 \mathrm{~cm} \mathrm{x} 0,53 \mathrm{~mm})$; gás de arraste: $\mathrm{N}_{2}$; fluxo do gás: $5,7 \mathrm{~mL} / \mathrm{min}$

Resposta local (folíolos da primeira folha trifoliolar)

Tempo (Horas após a última aplicação das soluções dos ácidos graxos, substratos de lipoxigenases)

\begin{tabular}{|c|c|c|c|c|c|c|c|c|}
\hline 0 & $5.633,0^{1} \mathbf{a A}$ & $5.660,0 \mathbf{a g}$ & $4.670,0 \underline{\mathbf{a}}$ & $5.696,7 \mathbf{a}$ & $3.982,0 \underline{\mathbf{B}}$ & $5.990,0 \underline{\mathbf{d g}}$ & $6.986,0 \mathbf{e}$ & $6.991,7$ e \\
\hline 24 & $6.362,7 \mathbf{b}$ & $17.573,3 \underline{\mathbf{b}}$ & $8.057,7 \mathbf{c h} \underline{\mathbf{A}}$ & $10.120,3 \mathbf{~ c h B}$ & $4.324,7 \underline{\mathbf{e B}}$ & $10.184,3 \mathbf{f C}$ & $8.147,0$ fhC & 7.091,7fhbD \\
\hline 48 & $5.976,3 \underline{\mathbf{c}} \mathbf{A}$ & $7.325,7 \mathbf{~ d i}$ & $7.224,3 \mathbf{~ d i \mathbf { A }}$ & 7.427,3 djo & $7.021,3 \underline{\mathbf{f}}$ & $12.642,0 \mathbf{g i C}$ & $7.323,3 \mathbf{g i C}$ & $6.529,0$ gjD \\
\hline
\end{tabular}

${ }^{1}$ Valores são a média das análises de três repetições. Nas colunas, as médias seguidas de uma mesma letra maiúscula (ou maiúscula grifada) não diferem entre si, a 5\% de probabilidade, pelo teste de Tukey. Nas linhas, as médias seguidas de uma mesma letra minúscula (ou minúscula grifada) não diferem entre si, a 5\% de probabilidade, pelo teste de Tukey.

Tabela 4. Níveis de hexanal presentes em extratos de folhas de soja, folíolos da segunda folha trifoliolar de plantas no estádio V3 de desenvolvimento. Variedade IAC-100 e genótipo IAC-100 TN coletados 0, 24 e $48 \mathrm{~h}$ após a última aplicação de solução $10 \mathrm{mM}$ dos ácidos araquidônico $\left(\mathrm{C}_{20: 4}\right)$, linoléico $\left(\mathrm{C}_{18: 2}\right)$ e linolênico $\left(\mathrm{C}_{18: 3}\right)$ e seus respectivos controles [aplicação de solução aquosa de Triton X-100 0,01\% (v/v)]. Condições experimentais: iguais às da Tabela 3

Resposta local (folíolos da segunda folha trifoliolar)

Tempo (Horas após a última aplicação das soluções dos ácidos graxos, IAC-100 IAC-100 TN substratos de lipoxigenases)

\begin{tabular}{|c|c|c|c|c|c|c|c|c|}
\hline 0 & $13.431,0^{1} \mathbf{A}$ & $12.198,7$ & $14.821,3 \underline{\mathbf{A}}$ & $10.800,7$ B & $4.686,0 \mathbf{b}$ & $4.701,9 \mathbf{b}$ & $5.769,0 \underline{\mathbf{b}}$ & $5.700,7 \underline{\mathbf{b}}$ \\
\hline 24 & $14.886,0 \mathbf{a}$ & $17.746,3$ & $14.586,3 \mathbf{a A}$ & $10.739,7 \mathbf{B}$ & $5.122,3$ & $11.788,0$ & $7.449,0 \mathbf{c}$ & $8.049,3 \bar{c}$ \\
\hline 48 & $13.049,3 \mathbf{A}$ & $8.652,3$ & $9.846,0 \underline{\mathbf{a}}$ & $10.070,7 \underline{\mathbf{a} B}$ & $7.846,3$ & $13.862,7 \underline{\mathbf{c}}$ & $8.236,7$ & $12.102,33 \underline{\mathbf{c}}$ \\
\hline
\end{tabular}

Ver rodapé da Tabela 3. As médias que não estão seguidas de letras não apresentam interação significativa, a 5\% de probabilidade, pelo teste de Cocharan e Bartlett.

níveis de hexanal 48 h após a última aplicação dos ácidos graxos, substratos de lipoxigenases.

Não houve aumento significativo de aldeídos totais 48 h após tratamentos, em ambos os genótipos analisados, tanto na resposta local (Tabela 5) quanto na sistêmica (Tabela 6).

\section{CONCLUSÃO}

Os resultados do estudo bioquímico e cinético das isoenzimas lipoxigenases de folhas dos dois genótipos analisados, utilizando o ácido linoléico como substrato, mostram a existência de dois picos mais acentuados de atividade específica de lipoxigenases a $\mathrm{pH} 4,5 \mathrm{e}$ 6,0 , nos tratamentos e nos respectivos controles, tanto na resposta local quanto na sistêmica, revelando a presença de mais de uma forma de isoenzima lipoxigenase no "pool" analisado. O valor da temperatura ótima a pH 6,0 em respostas local e sistêmica foi $25^{\circ} \mathrm{C}$.

Os resultados de atividade específica sugerem uma resposta da planta de soja à aplicação de ácidos graxos, substratos de lipoxigenases, pelo aumento da atividade, e mostram ainda que a remoção genética das isoenzimas lipoxigenases da semente não afetou a resposta da planta ao tratamento, uma vez que os genótipos apresentaram comportamento semelhante.

Os resultados mostram que, para ambos os genótipos analisados, tanto a produção de aldeídos totais quanto a produção de hexanal, em resposta à aplicação de ácidos graxos, substratos de lipoxigenases, foi pequena. Isto indica que a "Via das Lipoxigenases" está sendo ativada, mas não segue a via de produção de aldeídos proposta por Gardner ${ }^{29}$ e Croft et al. ${ }^{30}$. É possível que haja ativação da "Via das Lipoxigenases" em resposta à aplicação de ácidos graxos, e após a formação de hidroperóxidos, produtos primários das lipoxigenases, ocorre a ação enzimática de uma hidroperóxido ciclase seguindo a via de produção de ácido jasmônico com subseqüente ativação e expressão de genes que codificam inibidores de proteases.

A caracterização dos parâmetros cinéticos e bioquímicos de lipoxigenases presentes nas folhas de soja, bem como a elucidação de suas funções fisiológicas é de importância fundamental nas estratégias de manipulação genética que têm como objetivos a criação de cultivares de soja resistentes a insetos e patógenos. 
Tabela 5. Níveis de aldeídos totais presentes em extratos de folhas de soja, folíolos da primeira folha trifoliolar de plantas no estádio V3 de desenvolvimento. Variedade IAC-100 e genótipo IAC-100 TN coletados 0,24 e 48 h após a última aplicação de solução 10 mM dos ácidos araquidônico $\left(\mathrm{C}_{20: 4}\right)$, linoléico $\left(\mathrm{C}_{18: 2}\right)$ e linolênico $\left(\mathrm{C}_{18: 3}\right)$ e seus respectivos controles [aplicação de solução aquosa de Triton $\mathrm{X}-100$ 0,01\% (v/v)]. Condições experimentais: $0,5 \mathrm{~mL}$ de extrato foliar; $0,5 \mathrm{~mL}$ de solução de $\mathrm{MBTH} 0,1 \% ; 1,25 \mathrm{~mL} \mathrm{de} \mathrm{FeCl}_{3} 0,23 \% ; 3 \mathrm{~mL} \mathrm{CH}_{3} \mathrm{COCH}_{3}$.

\begin{tabular}{|c|c|c|c|c|c|c|c|c|}
\hline \multirow{3}{*}{$\begin{array}{l}\text { Tempo (Horas } \\
\text { após a última } \\
\text { aplicação das } \\
\text { soluções dos } \\
\text { ácidos graxos, } \\
\text { substratos de } \\
\text { lipoxigenases) }\end{array}$} & \multicolumn{8}{|c|}{ Resposta local (folíolos da primeira folha trifoliolar) } \\
\hline & \multicolumn{4}{|c|}{ IAC-100 } & \multicolumn{4}{|c|}{ IAC-100 TN } \\
\hline & Controle & $\begin{array}{c}\text { Ácido } \\
\text { Araquidônico }\end{array}$ & $\begin{array}{c}\text { Ácido } \\
\text { Linoléico }\end{array}$ & $\begin{array}{c}\text { Ácido } \\
\text { Linolênico }\end{array}$ & Controle & $\begin{array}{c}\text { Ácido } \\
\text { Araquidônico }\end{array}$ & $\begin{array}{c}\text { Ácido } \\
\text { Linoléico }\end{array}$ & $\begin{array}{c}\text { Ácido } \\
\text { Linolênico }\end{array}$ \\
\hline 0 & $0,8944 \mathbf{a}$ & $0,8981 \mathbf{a}$ & $0,8920 \mathbf{a}$ & $0,8940 \mathbf{a A}$ & $0,9294 \underline{\mathbf{b A}}$ & $0,9391 \underline{\mathbf{b}}$ & $0,9400 \underline{\mathbf{b}}$ & $0,9291 \underline{\mathbf{b}}$ \\
\hline 24 & $0,9420^{1} \underline{\mathbf{c}}$ & $1,1278 \underline{\mathbf{a}}$ & $1,1331 \underline{\mathbf{a}}$ & $0,8857 \mathbf{A}$ & $0,9335 \underline{\mathbf{c A}}$ & 1,1815 & $1,0213 \overline{\mathbf{B}}$ & $0,9970 \underline{\overline{\mathbf{B}}}$ \\
\hline 48 & $1,0419 \mathbf{b d}$ & $1,1088^{-}$ & 0,9886 & $1,0590 \mathbf{b}$ & $1,0274 \overline{\mathbf{c d}}$ & 1,2140 & $1,0423 \mathbf{c B}$ & $0,9835 \underline{\overline{\mathbf{B}}}$ \\
\hline
\end{tabular}

Ver rodapé da Tabela 4

Tabela 6. Níveis de aldeídos totais presentes em extratos de folhas de soja, folíolos da segunda folha trifoliolar de plantas no estádio V3 de desenvolvimento. Variedade IAC-100 e genótipo IAC-100 TN coletados 0,24 e 48 h após a última aplicação de solução 10 mM dos ácidos araquidônico $\left(\mathrm{C}_{20: 4}\right)$, linoléico $\left(\mathrm{C}_{18: 2}\right)$ e linolênico $\left(\mathrm{C}_{18: 3}\right)$ e seus respectivos controles [aplicação de solução aquosa de Triton $\mathrm{X}-100$ 0,01\% $(\mathrm{v} / \mathrm{v})$ ]. Condições experimentais: $0,5 \mathrm{~mL}$ de extrato foliar; $0,5 \mathrm{~mL}$ de solução de $\mathrm{MBTH} 0,1 \% ; 1,25 \mathrm{~mL} \mathrm{de} \mathrm{FeCl}_{3} 0,23 \% ; 3 \mathrm{~mL} \mathrm{CH}_{3} \mathrm{COCH}_{3}$

\begin{tabular}{|c|c|c|c|c|c|c|c|c|}
\hline \multirow{3}{*}{$\begin{array}{l}\text { Tempo (Horas } \\
\text { após a última } \\
\text { aplicação das } \\
\text { soluções dos } \\
\text { ácidos graxos, } \\
\text { substratos de } \\
\text { lipoxigenases) }\end{array}$} & \multicolumn{8}{|c|}{ Resposta local (folíolos da segunda folha trifoliolar) } \\
\hline & \multicolumn{4}{|c|}{ IAC-100 } & \multicolumn{4}{|c|}{ IAC-100 TN } \\
\hline & Controle & $\begin{array}{c}\text { Ácido } \\
\text { Araquidônico }\end{array}$ & $\begin{array}{c}\text { Ácido } \\
\text { Linoléico }\end{array}$ & $\begin{array}{c}\text { Ácido } \\
\text { Linolênico }\end{array}$ & Controle & $\begin{array}{c}\text { Ácido } \\
\text { Araquidônico }\end{array}$ & $\begin{array}{c}\text { Ácido } \\
\text { Linoléico }\end{array}$ & $\begin{array}{c}\text { Ácido } \\
\text { Linolênico }\end{array}$ \\
\hline 0 & $0,8726 \mathbf{a}$ & $0,8859 \mathbf{a}$ & $0,8808 \mathbf{a}$ & $0,8820 \mathbf{a}$ & $0,8450 \mathbf{b}$ & $0,8398 \mathbf{b}$ & $0,8419 \mathbf{b}$ & $0,8460 \mathbf{b}$ \\
\hline 24 & $1,0385^{1} \underline{\mathbf{a}}$ & 0,9644 & $1,0294 \underline{\mathbf{a}}$ & 1,1588 & 0,9006 & 1,0572 & $0,9448 \mathbf{A}$ & 0,9264 \\
\hline 48 & 0,9185 & 0,9906 & 0,8934 & 1,0334 & $1,0433 \underline{\mathbf{b}}$ & $1,0516 \underline{\mathbf{b}}$ & $0,9523 \mathbf{A}$ & 1,0064 \\
\hline
\end{tabular}

Ver rodapé da Tabela 4

\section{AGRADECIMENTOS}

Os autores agradecem à Fundação de Amparo à Pesquisa do Estado de Minas Gerais, FAPEMIG, pelo apoio financeiro.

\section{REFERÊNCIAS}

1. Siedow, J. N.; Annu. Rev. Plant Physiol. Plant Mol. Biol. 1991, 42, 145.

2. Matsui, K.; Hijiya, K.; Tabuchi, Y.; Kajiwara, T.; Plant Physiol. 1999, 119, 1279.

3. Rouet-Mayer, M.; Bureau, J.; Laurieri, C.; Plant Physiol. 1992, 98, 971.

4. Stephenson, L. C.; Bunker, T. W.; Dubbs, W. E.; Grimes, H. D.; Plant Physiol. 1998, 116, 923.

5. Park, T. K.; Holland, M. A.; Laskey, J. G.; Polacco, J. C.; Plant Sci. 1994, 96, 109.

6. Vieira, A. A.; Oliveira, M. G. A.; José, I. C.; Piovesan, N. D.; Rezende, S. T.; Moreira, M. A.; Barros, E. G.; Rev. Bras. Fisiol. Veg. 2001, 13, 1.

7. Fidantsef, A. L.; Bostock, R. M.; Physiol. Plant. 1998, 102, 257.

8. Wang, C.; Kevan, P. C.; Croft, J. U.; Hildebrand, D. F.; Plant Physiol. 1999, $37,497$.

9. Hildebrand, D. F.; Hamilton-Kemp, T. R.; Legg, C. S.; Bookjans, G.; Curr. Top. Plant Biochem. Physiol. 1988, 7, 201.

10. Farmer, E. E.; Ryan, C. A.; Plant Cell 1992, 4, 129.

11. Zimmerman, D. C.; Coudron, C. A.; Plant Phisiol. 1979, 63, 636

12. Mueller, M. J.; Physiol. Plant. 1997, 100, 653.

13. Grimes, H. D.; Koetje, D. S.; Franceschi, V. R.; Plant Physiol. 1992, 100, 433.

14. Fornaroli, S.; Petrussa, E.; Braidot, E.; Vianello, A.; Macrì, F.; Plant Sci. 1999, 145,1 .
15. Fehr, W. R.; Caviness, C. E.; Stages of Soybean Development, Ames: Cooperative Extension Service, Iowa State University, 1977, p. 11.

16. Ohta, H.; Ida, S.; Mikami, B.; Morita, Y.; Plant Cell Physiol. 1986, 22 , 911.

17. Axelrod, B.; Cheesbrough, T. M.; Laasko, S.; Methods Enzymol. 1981, 71, 441.

18. Smith, P. K.; Krohn, R. I.; Hermanson, G. T.; Mallia, A. K.; Gartner, F. H.; Provenzano, M. D.; Fujimoto, E. K.; Goeke, N. M.; Olson, B. J.; Klenk, D. C.; Anal. Biochem. 1985, 15, 76.

19. Kakade, M. L.; Rackis, J. J.; Mcghee, J. E.; Puski, G.; Cereal Chem. 1974, 51,376

20. Utumi, M. M.; Barros, E. G.; Oliveira, M. G. A.; Sediyama, C. S.; Moreira, M. A.; Rev. Bras. Fisiol. Veg. 1998, 10, 203.

21. Santos, I. C.; Reis, W. J. P.; Moreira, M. A.; Rezende, S. T.; Rocha, V. S.; Sediyama, C. S.; Rev. Ceres 1993, 40, 438

22. Galliard, T.; Phillips, D.R.; J. Biochem. 1971, 124, 431.

23. Leoni, O.; Iori, R.; Palmieri, S.; J. Food Sci. 1985, $50,88$.

24. Koch, E.; Meier, B.; Eiben, H.-G.; Slusarenko, A.; Plant Physiol. 1992, 99, 571.

25. Avdiushiko, S. A.; Ye, X. S.; Kue, J.; Hildebrand, D.F.; Plant 1994, 193, 349.

26. Minguez-Mosqueira, M. I.; Jaren-Galan, M.; Garrido-Fernandez, J.; Phytochemistry 1993, 32, 1103.

27. Redgel, D.; Schewe, T.; Kuehn, H.; Biochem. 1995, 60, 715.

28. Lanna, A. C.; Oliveira, M. G. A.; Barros, E. G.; Moreira, M. A.; Braz. J. Plant Physiol. 1996, 8, 87.

29. Gardner, H. W.; Biochim. Biophys. Acta 1991, 1084, 221.

30. Croft, K. P. C.; Jüttner, F.; Slusarenko, A. J.; Plant Physiol. 1993, 101, 13. 